Background: Real-world evidence on achieving treatment targets with apremilast (APR) in patients (pts) with PsA is limited. In the phase 3 PALACE trials, pts reached remission (REM)/low disease activity (LDA) targets at 52 wks most frequently when early APR treatment was initiated and pts were in moderate disease activity, as measured by Clinical Disease Activity Index for PsA (cDAPSA) score. In APPRAISE, we assessed APR effectiveness/tolerability in pts with PsA in routine clinical practice in Canada.

Objectives: This interim efficacy analysis focused on the available data on APR effectiveness measuring rate of achieving cDAPSA REM or LDA at 12 mos and Pt Acceptable Symptom Status (PASS) results.

Methods: The prospective, multicenter, observational APPRAISE study assessed APR effectiveness/tolerability in adults with active PsA in routine clinical care enrolled from July 2018-March 2020. Pts were followed from treatment initiation to 12 mos, with visits suggested every 4 mos. The primary effectiveness endpoint was the rate of achieving at least LDA (cDAPSA <14) at 12 mos. Pt-reported outcome measures were assessed. Data reported are as observed in pts continuing APR treatment.

Results: In total, 101 pts were enrolled in APPRAISE. Mean age was 52 yrs; $56 \%$ were women. Mean (SD) PsA duration at baseline (BL) was 6 (8) yrs. Oligoarticular disease ( $\leq 4$ joint involvement) was most common (41\%), followed by polyarticular (35\%). Most pts (92\%) received prior conventional DMARDs and 17\% received prior biologic therapy; concomitant MTX was reported in $41 \%$ at BL. By 12 mos, 41/101 enrolled pts discontinued, 35 reached 12 mos follow-up (4 mos: $n=92 ; 8$ mos: $n=61)$, and 25 have yet to reach 12 mos. The majority $(92 \%)$ of discontinuations due to lack/loss of effectiveness or AEs occurred within 4-8 mos. AEs were primarily Gl related early in treatment. The proportion of pts with continued APR achieving CDAPSA REM/LDA treatment targets increased significantly over time (Figure 1). Significant reductions were seen over 12 mos in swollen/tender joint counts and plaque psoriasis, with reduced mean (SD) body surface area of $-4 \%$ $(9 \%)$ (Table 1). Prevalence of dactylitis/enthesitis at BL, 4, 8, and 12 mos was $17 \% / 33 \%, 9 \% / 24 \%, 5 \% / 19 \%$, and $0 \% / 21 \%$, respectively. Pain assessment (VAS) significantly improved over time. The proportion of pts achieving PASS with continued APR increased significantly over 12 mos (BL: 27\%; 12 mos: 65\%) (Figure 1). COVID restrictions impacted in-office assessment visits, necessitating reliance on virtual visits.

Conclusion: Pts with PsA receiving APR were assessed at regular intervals in routine clinical care in Canada. This interim analysis revealed a greater number of pts receiving APR (66\%) who completed the 12-mo follow-up achieved REM or LDA, as measured by CDAPSA over 12 mos. A majority of pts $(65 \%)$ reported satisfaction with their disease state, as measured by PASS. No new safety signals were observed.

Table 1. Change in Clinical Parameters and Pt-Reported Outcomes From BL to 4,8 , and 12 Mos

Outcome Measure ${ }^{\star}$ Mean (SD)BL $(n=101) 4 \operatorname{Mos}(n=92) 8 \operatorname{Mos}(n=61) 12 \operatorname{Mos}(n=35)$

\begin{tabular}{lllll}
\hline $\begin{array}{l}\text { Disease/Clinical Parameters } \\
\text { Tender joint count (0-68) }\end{array}$ & $7.5(6.7)$ & $-2.5(6.3)^{\star}$ & $-3.9(5.2)^{\star}$ & $-2.2(6.4)$ \\
Swollen joint count (0-66) & $5.4(5.4)$ & $-3.0(4.5)^{\star}$ & $-3.1(4.3)^{\star}$ & $-3.1(4.4)^{\star}$ \\
PhGA & $42.9(18.8)$ & $-19.0(24.6)^{\star}$ & $-24.2(24.2)^{\star}$ & $-21.2(26.3)^{\star}$ \\
$\quad \begin{array}{llll}\text { Body surface area, \% } \\
\quad \text { cDAPSA }\end{array}$ & $3.1(6.1)$ & $-2.2(6.0)^{\star}$ & $-2.7(7.5)^{\star}$ & $-4.2(9.1)^{\star}$ \\
Pt-Reported Outcomes & $22.2(13.3)$ & $-7.9(12.1)^{\star}$ & $-10.1(13.5)^{\star}$ & $-6.9(12.0)^{\star}$ \\
PtGA, mm & & & & \\
Pain, mm & $50.0(24.6)$ & $-10.2(27.5)^{\star}$ & $-9.1(31.9)^{\star}$ & $-3.6(39.7)$ \\
HAQ-DI & $48.3(25.3)$ & $-9.5(26.2)^{\star}$ & $-12.2(28.7)^{\star}$ & $-7.3(26.0)$ \\
& $0.9(0.7)$ & $-0.13(0.5)^{\star}$ & $-0.15(0.6)$ & $-0.1(0.7)$
\end{tabular}

${ }^{*}$ Denotes significant change from BL $(P<0.05)$ from paired-sample $t$-tests; note that mean change from $B L$ may be greater than the mean $B L$ value when improvements of large magnitude, for pts with relatively elevated BL values, are observed in samples with lower n's. HAQ-DI = Health Assessment Questionnaire-Disability Index; PhGA = Physician's Global Assessment; PtGA = Patient's Global Assessment.

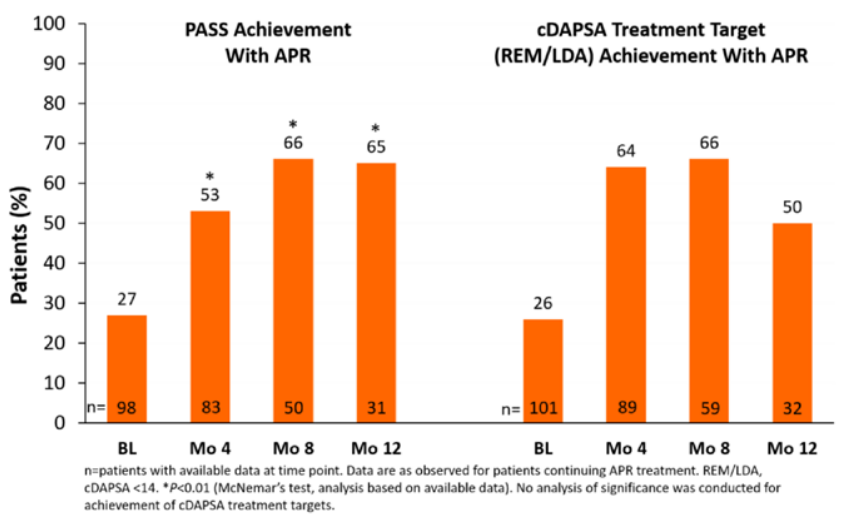

Acknowledgements: This study was funded by Celgene and Amgen Inc. Writing support was funded by Amgen Inc. and provided by Kristin Carlin, RPh, MBA, of Peloton Advantage, LLC, an OPEN Health company.

Disclosure of Interests: Vinod Chandran Consultant of: AbbVie, Amgen, BMS, Celgene Corporation, Eli Lilly, Janssen, Novartis, Pfizer, UCB, Grant/ research support from: AbbVie, Amgen, BMS, Celgene Corporation, Eli Lilly, Janssen, Novartis, Pfizer, UCB, Louis Bessette Consultant of: AbbVie, Amgen, BMS, Celgene Corporation, Eli Lilly, Janssen, Merck, Pfizer, Sanofi, Novartis, UCB, Grant/research support from: AbbVie, Amgen, BMS, Celgene Corporation, Eli Lilly, Janssen, Merck, Pfizer, Sanofi, Novartis, UCB, Carter Thorne Speakers bureau: AbbVie, Amgen, Celgene Corporation, Eli Lilly, Medexus/ Medac, Merck, Novartis, Pfizer, Sandoz, Sanofi, Consultant of: Centocor Medexus/Medac, Merck, Grant/research support from: Novartis, Pfizer, Maqbool Sheriff Speakers bureau: AbbVie, Celgene Corporation, Eli Lilly, Janssen Merck, Pfizer, Sandoz, Proton Rahman Speakers bureau: AbbVie, Amgen, Celgene, Eli Lilly, Janssen, Merck, Novartis, Pfizer, UCB, Dafna D Gladman Consultant of: AbbVie, Amgen, BMS, Celgene Corporation, Eli Lilly, Galapagos, Gilead, Janssen, Novartis, Pfizer, UCB, Grant/research support from: AbbVie, Amgen, BMS, Celgene Corporation, Eli Lilly, Galapagos, Gilead, Janssen, Novartis, Pfizer, UCB, Sabeen Anwar Consultant of: AbbVie, Amgen Inc., BMS, Novartis, and Pfizer, Grant/research support from: AbbVie, Amgen Inc., Eli Lilly, Janssen, and Pfizer, Jennifer Jelley Employee of: Amgen Canada Inc., Anne-Julie Gaudreau Employee of: Amgen Canada Inc., Manprit Chohan Employee of: Amgen Canada Inc., John S. Sampalis Employee of: JSS Medical Research.

DOI: 10.1136/annrheumdis-2021-eular.2599

\section{AB0558 \\ CLINICAL EFFECTIVENESS AND SAFETY OF ADALIMUMAB VERSUS NON-BIOLOGIC THERAPY IN PSORIATIC ARTHRITIS PATIENTS OVER 24 MONTHS - RESULTS OF THE COMPLETE-PSA CANADIAN OBSERVATIONAL STUDY}

M. Khraishi ${ }^{1}$, J. Stewart ${ }^{2}$, Y. Setty ${ }^{3}$, M. C. Laliberté ${ }^{4}$, L. Bessette ${ }^{5} .{ }^{1}$ Memorial University of Newfoundland, Memorial University of Newfoundland, St. John's, Canada; ${ }^{2}$ University of British Columbia, University of British Columbia, Penticton, Canada; ${ }^{3}$ Grey Bruce Health Services, Grey Bruce Health Services, Owen Sound, Canada; ${ }^{4}$ AbbVie Corporation, AbbVie Corporation, Montreal, Canada; ${ }^{5}$ Laval University, Centre Hospitalier de l'Université Laval, Laval University, Centre Hospitalier de I'Université Laval, Quebec City, Canada

Background: COMPLETE-PSA was an observational study of biologic-naïve Canadian adults with active psoriatic arthritis (PSA) treated with adalimumab or non-biologic disease-modifying anti-rheumatic drugs (nbDMARD) after switch from initial therapy.

Objectives: The aim of this analysis was to assess the 24-month clinical effectiveness and safety of adalimumab vs. nbDMARD in the treatment of PsA in a real-life setting.

Methods: Eligible patients were biologic naïve adults, with active PsA who required change in their treatment regimen due to inadequate response or intolerance, per the judgment of the treating physician. Patients were enrolled between July/2011 and December/2017 and followed for up to 24 months. Patients were treated as per routine care. The primary endpoint, change in DAS-28 to month 24 , was assessed with baseline-adjusted multivariable models and the least square mean (LSM) estimates were generated; Physician's Global Assessment of disease activity (PGA, 100mm VAS) was assessed using similar methodology. Probability of achieving the following therapeutic response thresholds was ascertained and odds ratios (ORs) were generated: $50 \% / 70 \%$ improvement in the American College of Rheumatology criteria (ACR50/ACR70), DAS-28<3.2 (low disease activity or remission; LDA/ remission), DAS-28<2.6 (remission), modified minimal disease activity (mMDA: achievement of $5 / 7$ of: TJC and SJC $\leq 1$ each, BSA $\leq 3 \%$, pain $\leq 15$ (VAS, mm) Patient Global Assessment [PtGA] $\leq 20, \mathrm{HAQ}-\mathrm{DI} \leq 0.5$, and no enthesitis), and psoriasis ( $\mathrm{PsO}$ ) BSA $<3 \%$.

Results: A total of 277 adalimumab and 148 nbDMARD- treated patients were included as part of the intent-to-treat population. Baseline methotrexate was reported by $61.7 \%$ and $81.1 \%$ of adalimumab and nbDMARD-treated patients, respectively. PsO BSA at baseline was predominantly $<3 \%$ for both adalimumab (60.2\%) and nbDMARD (64.6\%) patients. Adalimumab-treated patients reported significantly $(p<0.05)$ higher mean (SD) disease activity for both DAS-28 [4.8 (1.2) vs. 4.3 (1.1)] and PGA [59.4 (19.5) vs. $51.0(21.8) \mathrm{mm}]$ at baseline.

For the primary endpoint, baseline-adjusted month 24 DAS-28 levels were significantly lower for adalimumab vs. nbDMARD patients [LSM $(95 \% \mathrm{Cl}): 2.4(2.2-2.6)$ vs. $3.0(2.7-3.3) ; p=0.037]$. In addition, rapid and sustained reductions in DAS-28 were observed for adalimumab-treatment patients, with overall treatment effect significant $(p<0.001)$ in favor of adalimumab [estimate $(95 \% \mathrm{Cl}):-1.1(-1.4,-0.7)$ ] similar results were observed for PGA $[-12.9(-1.7,-8.0)]$. Adalimumab-treated 
patients were at significantly higher $(p<0.001)$ odds of attaining therapeutic response thresholds compared to DMARD-treated patients, specifically: DAS$28 \mathrm{LDA} /$ remission [OR $(95 \% \mathrm{Cl}): 4.5(2.8,7.3)$ ] or remission [OR $(95 \% \mathrm{Cl}): 4.1$ (2.7-6.3)], ACR50 [OR (95\% Cl): $3.0(2.0-4.6)$ ], ACR70 [OR (95\% Cl): 3.1 (2.04.9)], mMDA [OR (95\% Cl): 2.4 (1.6-3.6)], and PsO BSA <3\% [OR (95\% Cl): 2.2 $(1.2-3.7)]$

Overall, $32(10.7 \%)$ of adalimumab-treated patients reported 86 AEs, the most common related to infections [16 events in 10 (3.3\%) patients].

Conclusion: Real-world treatment with adalimumab was more effective in improving disease activity and psoriasis severity, over 24 months when compared to nbDMARDs and was associated with significantly greater likelihood of achieving minimal disease activity. Observed AEs were consistent with the established safety profile of adalimumab.

Disclosure of Interests: Majed Khraishi Speakers bureau: Speaker for AbbVie, Consultant of: Consultant for AbbVie, Grant/research support from: Principal Investigator for AbbVie, Jacqueline Stewart Speakers bureau: Speaker for Abbvie, Janssen, and Johnson \& Johnson, Consultant of: Advisory Board Consultant for AbbVie, Amgen, Celgene, Merck, Novartis, Pfizer, and Sanofi-Genzyme; Grant/research support from: Participated in research with AbbVie, Bristol Myers Squibb, Janssen, and Roche, Yatish Setty Consultant of: Advisory Board meetings with AbbVie and Janssen, Marie-Claude Laliberté Employee of: Employee of AbbVie, Louis Bessette Speakers bureau: Speaker for Amgen, BMS, Janssen, UCB, AbbVie, Pfizer, Merck, Celgene, Lilly, Novartis, Gilead, Sandoz, and Fresenius Kabi, Consultant of: Consultant for Amgen, BMS, Janssen, UCB, AbbVie, Pfizer, Celgene, Lilly, Novartis, Gilead, Sandoz, Samsung Bioepis, and Fresenius Kabi, Grant/research support from: Investigator for Amgen, BMS, Janssen, UCB, AbbVie, Pfizer, Merck, Celgene, Sanofi, Lilly, Novartis, and Gilead.

DOI: 10.1136/annrheumdis-2021-eular.2644

\section{AB0559 1 EFFICACY AND SAFETY OF RISANKIZUMAB IN PATIENTS WITH ACTIVE PSORIATIC ARTHRITIS AFTER INADEQUATE RESPONSE OR INTOLERANCE TO DMARDS: 24-WEEK RESULTS FROM THE PHASE 3, RANDOMIZED, DOUBLE-BLIND KEEPSAKE 1 TRIAL}

L. E. Kristensen ${ }^{1}$, M. Keiserman ${ }^{2}$, K. Papp ${ }^{3}$, L. Mccasland ${ }^{4}$, D. White ${ }^{5}$ L. Barcomb ${ }^{6}$, W. Lu ${ }^{6}$, Z. Wang ${ }^{6}$, A. M. Soliman ${ }^{6}$, A. Eldred ${ }^{6}$, F. Behrens ${ }^{7}$. ${ }^{1}$ Copenhagen University, The Parker Institute, Copenhagen, Denmark; ${ }^{2}$ Pontifical Catholic University, Rheumatology Section, Porto Alegre, Peru; ${ }^{3}$ Probity Medical Research, K Papp Clinical Research, Waterloo, Canada; ${ }^{4}$ Loyola University Medical Center, Department of Rheumatology, Maywood, United States of America; ${ }^{5}$ Waikato Hospital, Rheumatology Department, Hamilton, New Zealand; ${ }^{6}$ AbbVie, Inc, Not Applicable, North Chicago, United States of America; ${ }^{7}$ Goethe University Frankfurt, CIRI/Rheumatology \& Fraunhofer Institute for Translational Medicine and Pharmacology ITMP, Frankfurt, Germany

Background: Risankizumab (RZB) is a humanized immunoglobulin G1 monoclonal antibody that specifically inhibits interleukin 23 by binding to its $p 19$ subunit. RZB is being investigated as a treatment for adults with psoriatic arthritis (PsA).

Objectives: To compare the efficacy and safety of RZB vs placebo (PBO) for the treatment of active PsA in patients who have had inadequate response or intolerance to $\geq 1$ conventional synthetic disease modifying antirheumatic drug (csDMARD-IR).

Methods: In KEEPsAKE 1 (NCT03675308), eligible adults (csDMARD-IR with $\geq 5$ swollen joints [SJC] and $\geq 5$ tender joints [TJC]) were randomized (1:1) to receive blinded subcutaneous RZB $150 \mathrm{mg}$ or PBO at weeks 0,4 , and 16 . The primary endpoint was the proportion of patients achieving $20 \%$ improvement in American College of Rheumatology score (ACR20) at week 24. Ranked secondary and other secondary endpoints are shown in the Table 1. Safety was assessed throughout the study. Results reported here are from the 24-week double-blind period; the open-label period with all patients receiving RZB is ongoing.

Results: 964 patients (RZB, $N=483$; PBO, $N=481$ ) were evaluated at week 24 . Demographics and baseline characteristics were generally balanced between treatment groups (mean duration of PSA: 7.12 years; mean SJC: 12.2; mean TJC: 20.6; mean body surface area involved with psoriasis $[B S A]$ in patients with $B S A \geq 3 \%$ : $16.7 \%)$. A significantly greater proportion of RZB- vs PBO-treated patients $(57.3 \%$ and $33.5 \%$, respectively) achieved the primary endpoint of ACR20 at week 24 ( $P$ $<.001$; Table 1). Significant differences were also observed for RZB vs PBO for the first 8 ranked secondary endpoints $(P<.001$ for all; Table 1$)$. Serious adverse events were reported for $2.5 \%$ and $3.7 \%$ of RZB- and PBO-treated patients, respectively; serious infections were reported for $1.0 \%$ and $1.2 \%$. There was 1 death in the RZB group.
Conclusion: RZB resulted in significantly greater improvements in signs and symptoms of PsA compared with $\mathrm{PBO}$ and was well tolerated in patients who were CSDMARD-IR

Table. Efficacy Results

\begin{tabular}{cccc}
\hline RZB $150 \mathrm{mg}$ & PBO & Difference & P value \\
$\mathrm{N}=483$ & $\mathrm{~N}=481$ & $(95 \% \mathrm{Cl})$ & \\
\hline
\end{tabular}

Primary endpoint

$57.3 \quad 33.5 \quad 24.0(18.0,30.0)<.001^{\star \star \star}$

Ranked secondary endpoints

\begin{tabular}{|c|c|c|c|c|}
\hline HAQ-DI, change & -0.3 & -0.1 & $-0.2(-0.3,-0.1)$ & $<.001^{\star \star \star \star *}$ \\
\hline PASI 90, ${ }^{a} \%$ & 52.3 & 9.9 & $42.5(35.6,49.3)$ & $<.001^{\star \star \star \star}$ \\
\hline ACR20 at week $16, \%$ & 56.3 & 33.4 & $23.1(16.8,29.4)$ & $<.001^{\star \star \star *}$ \\
\hline MDA, \% & 25.0 & 10.2 & $14.8(10.2,19.4)$ & $<.001^{* * * *}$ \\
\hline mNAPSI, ${ }^{a}$ change & -9.8 & -5.6 & $-4.2(-5.7,-2.7)$ & $<.001^{\star * *}$ \\
\hline PGA-F, change & -0.8 & -0.4 & $-0.4(-0.6,-0.3)$ & $<.001^{\star \star \star \star *}$ \\
\hline Resolution of enthesitis, a,b \% & 48.4 & 34.8 & $13.9(7.6,20.2)$ & $<.001^{\star \star \star *}$ \\
\hline Resolution of dactylitis, & 68.1 & 51.0 & $16.9(7.5,26.4)$ & $<.001^{\star \star \star *}$ \\
\hline PsA-mTSS, change & 0.2 & 0.3 & $-0.1(-0.4,0.2)$ & .50 \\
\hline SF-36 PCS, change & 6.5 & 3.2 & $3.3(2.4,4.2)$ & $<.001^{\dagger}$ \\
\hline FACIT-Fatigue, change & 6.5 & 3.9 & $2.6(1.5,3.7)$ & $<.001^{\dagger}$ \\
\hline \multicolumn{5}{|l|}{ Other Secondary Endpoints } \\
\hline ACR50, \% & 33.4 & 11.3 & $22.2(17.3,27.2)$ & $<.001^{\dagger}$ \\
\hline ACR70, \% & 15.3 & 4.7 & $10.5(6.9,14.2)$ & $<.001^{\dagger}$ \\
\hline
\end{tabular}

ACR20/ACR50/ACR70, 2 20/50/70\% improvement in American College of Rheumatology score; HAQ-DI, Health Assessment Questionnaire-Disability Index; FACIT-Fatigue, Functional Assessment of Chronic Illness Therapy-

Disclosure of Interests: Lars Erik Kristensen Speakers bureau: LK has received honoraria or fees for serving as a speaker or consultant from AbbVie, Amgen, Biogen, Bristol-Myers Squibb, Gilead, Janssen, Lilly, Merck, Novartis, Pfizer, and UCB., Consultant of: LK has received honoraria or fees for serving as a speaker or consultant from AbbVie, Amgen, Biogen, Bristol-Myers Squibb Gilead, Janssen, Lilly, Merck, Novartis, Pfizer, and UCB., MAURO KEISERMAN Speakers bureau: MK has received honoraria or fees for serving on advisory boards, as a speaker or as a consultant, and grants as a principal investigator from AbbVie, Amgen, Bristol-Myers Squibb, Celgene, GlaxoSmithKline, Janssen, Novartis, Pfizer, Roche, and UCB., Consultant of: MK has received honoraria or fees for serving on advisory boards, as a speaker or as a consultant, and grants as a principal investigator from AbbVie, Amgen, Bristol-Myers Squibb, Celgene, GlaxoSmithKline, Janssen, Novartis, Pfizer, Roche, and UCB., Grant/ research support from: MK has received honoraria or fees for serving on advisory boards, as a speaker or as a consultant, and grants as a principal investigator from AbbVie, Amgen, Bristol-Myers Squibb, Celgene, GlaxoSmithKline, Janssen, Novartis, Pfizer, Roche, and UCB., Kim Papp Speakers bureau: KP has received honoraria or fees for serving on advisory boards, as a speaker, and as a consultant, as well as grants as principal investigator from AbbVie, Amgen, Astellas, Bausch Health (Valeant), Baxalta, Baxter, Boehringer Ingelheim, Bristol-Myers Squibb, Celgene, Coherus, Dermira, EMD Serono, Forward Pharma, Galderma, Genentech, GlaxoSmithKline, Janssen, Kyowa Kirin, LEO Pharma, Lilly, Medlmmune, Merck, Novartis, Pfizer, Regeneron, Roche, Sanofi Genzyme, Stiefel, Sun Pharma, Takeda, and UCB., Consultant of: KP has received honoraria or fees for serving on advisory boards, as a speaker, and as a consultant, as well as grants as principal investigator from AbbVie, Amgen, Astellas, Bausch Health (Valeant), Baxalta, Baxter, Boehringer Ingelheim, Bristol-Myers Squibb, Celgene, Coherus, Dermira, EMD Serono, Forward Pharma, Galderma, Genentech, GlaxoSmithKline, Janssen, Kyowa Kirin, LEO Pharma Lilly, Medlmmune, Merck, Novartis, Pfizer, Regeneron, Roche, Sanofi Genzyme, Stiefel, Sun Pharma, Takeda, and UCB., Grant/research support from: $\mathrm{KP}$ has received honoraria or fees for serving on advisory boards, as a speaker, and as a consultant, as well as grants as principal investigator from AbbVie, Amgen, Astellas, Bausch Health (Valeant), Baxalta, Baxter, Boehringer Ingelheim, Bristol-Myers Squibb, Celgene, Coherus, Dermira, EMD Serono, Forward Pharma, Galderma, Genentech, GlaxoSmithKline, Janssen, Kyowa Kirin, LEO 